\title{
Optimizing Tannin Precipitation in Cashew Apple Juice
}

\author{
Trakul Prommajak $^{1^{*}}$, Noppol Leksawasdi ${ }^{2}$ \\ and Nithiya Rattanapanone ${ }^{2,3}$
}

\begin{abstract}
${ }^{1}$ Division of Food Safety in Agribusiness, School of Agriculture and Natural Resources, University of Phayao, Phayao 56000, Thailand

${ }^{2}$ Faculty of Agro-Industry, Chiang Mai University, Chiang Mai 50100, Thailand

${ }^{3}$ Postharvest Technology Research Institute, Chiang Mai University, Chiang Mai 50200, Thailand

*Corresponding author. E-mail: tpromjak@gmail.com

https://doi.org/10.12982/CMUJNS.2018.0002
\end{abstract}

\begin{abstract}
The juice extracted from cashew apples contains tannins that must be reduced due to their astringency and anti-nutritional properties. This study investigated reducing the tannins in cashew apple juice by mixing gelatin at 0.0 to $1.0 \%(w / v)$ with the juice for 5 to 15 min. Response surface methodology was used to simulate tannin concentration, turbidity, and weight of precipitate as a function of gelatin concentration and mixing time. All models were significant $(P<0.01)$ and residuals exhibited normal distribution. Increasing the gelatin concentration decreased tannins and juice turbidity. Optimal conditions for minimum concentration of tannins and turbidity were obtained by adding gelatin at $0.67 \%(w / v)$ for 15 min. Cashew apple juice with the tannins reduced could be used in the subsequent production of wine and bioethanol.
\end{abstract}

Keywords: Tannins, Gelatin, Cashew apple, Response surface methodology

\section{INTRODUCTION}

Cashew apples are cultivated primarily for their nuts-cashew nuts. The nuts represent only $10 \%$ of the total fruit weight, with the remainder typically left in the field as waste. However, juice from the cashew apple offers potential alternative uses, including fermenting into wine, probiotic beverages, and bioethanol (Prommajak et al., 2014).

Cashew apple juice contains high amounts of sugar (about 10\%) and ascorbic acid (280 $\mathrm{mg} / 100 \mathrm{ml}$ ) (Inyang and Abah, 1997; Figueiredo et al., 2002). However, the tannins in cashew apple juice $(0.6 \mathrm{mg} / 100 \mathrm{~g})$ cause an astringent taste (Rocha et al., 2007). Tannins are also an anti-nutritional factor, acting as metal ion chelators and digestion inhibitors (Hagerman, 2011). Tannins are phenolic compounds that are categorized into three groups: condensed tannins, hydrolysable tannins, and complex tannins. Condensed tannins can be hydrolyzed under harsh conditions and are responsible for the dry-mouth feeling in red wine (Vermerris and Nicholson, 2006). 
Researchers have studied the efficacy of microfiltration, tannase, and clarifying agents (sago, gelatin, polyvinyl pyrolidone, and starch) for removing tannins from cashew apple juice (Cormier, 2008). Campos et al. (2002) studied the shelf-life stability of cashew apple juice clarified by microfiltration associated with enzymatic hydrolysis $(0.1 \%$ of tannase enzyme $)$ to reduce astringency. Clarification was carried out on a tubular microfiltration module using polyethersulfone membranes $\left(0.3 \mu \mathrm{m}\right.$ pore size and $0.05 \mathrm{~m}^{2}$ of permeation area). Some chemicals such as tannase and polyvinyl pyrolidone are expensive and not readily available, and microfiltration is difficult to operate (Talasila et al., 2012).

As a result, using gelatin is one of the most popular methods for removing tannins from cashew apple juice. Gelatin and other proteins can interact with the tannins via hydrogen bond between phenolic groups of tannins and amino groups of proteins (Shahidi and Naczk, 2004). Gelatin can be added to the juice as either a powder or solution. Inyang and Abah (1997) added gelatin powder $(0.45 \mathrm{~g} / 100 \mathrm{ml})$ to the juice, stirred and allowed it to stand for $10 \mathrm{~min}$ to precipitate tannins. Talasila et al. (2012) investigated different levels of gelatin solutions (2.0 and $4.0 \% \mathrm{w} / \mathrm{v}$ ). None of these studies, however, nor any others to the best of our knowledge, investigated the optimum gelatin-to-juice ratio for tannin precipitation in cashew apple juice. This study, therefore, sought to determine the optimal gelatin concentration and mixing time for precipitating tannins in cashew apple juice using response surface methodology.

\section{MATERIALS AND METHODS}

\section{Cashew juice preparation}

Cashew apple was harvested at ripening stage (deep red color) from a local orchard in Uttaradit Province, Thailand. The samples were transported to the laboratory within $6 \mathrm{~h}$ and immediately frozen at $-22^{\circ} \mathrm{C}$. The fruit juice was obtained by a hydraulic press machine and then filtered through a double layer of muslin cloth. Potassium metabisulfite was added at a concentration of $50 \mathrm{mgL}^{-1}$ to inhibit wild yeasts and other microbes. Then, the juice was kept frozen at $-22^{\circ} \mathrm{C}$ until use. The juice was thawed at room temperature and then centrifuged at 2,370 $\times$ g for 10 min using Universal 320R (Hettich, Germany) to clarify the cashew apple juice. Gelatin (240 bloom, 40 mesh) was purchased from Gelita AG (Germany).

\section{Tannin precipitation}

Factorial design was employed to test the effects of adding gelatin and the mixing time on tannin concentration and turbidity of cashew apple juice, as well as the amount of gelatintannin precipitate. Gelatin powder was added into $30 \mathrm{ml}$ of cashew juice in a $125 \mathrm{ml}$ flask at the concentrations of 0.0 (null), $0.2,0.4,0.6,0.8$, and $1.0 \%(\mathrm{w} / \mathrm{v})$. The flask was shaken at 100 rpm in a Ratek OM11 orbital mixer/incubator (Ratek Instruments, Australia). The mixture was pipetted out at 5, 10, and $15 \mathrm{~min}$ and then centrifuged at $2,000 \times \mathrm{g}$ for $10 \mathrm{~min}$ at $25^{\circ} \mathrm{C}$ (Mikro 22 $\mathrm{R}$, Hettich, Germany). The supernatant was kept to determine condensed tannins and turbidity. The precipitate was washed with $5 \mathrm{ml}$ distilled water, re-suspended, and centrifuged using the above conditions to remove supernatant and dried in a hot air oven at $105^{\circ} \mathrm{C}$ for $48 \mathrm{~h}$. The experiment was performed in triplicate. 


\section{Determination of condensed tannin}

The condensed tannins in cashew apple were analyzed by butanol-HCl method (Vermerris and Nicholson, 2006). In brief, a $0.25 \mathrm{ml}$ sample was mixed with butanol-HCl reagent $\left(77 \mathrm{mg}\right.$ of $\mathrm{FeSO}_{4} \cdot 7 \mathrm{H}_{2} \mathrm{O}$ in $500 \mathrm{ml}$ of $\mathrm{HCl}$ and $n$-butanol at a volume ratio of 2:3). The sample was placed in a water bath at $95^{\circ} \mathrm{C}$ for $15 \mathrm{~min}$. The absorbance at $530 \mathrm{~nm}$ was analyzed by Anthos Zenyth microplate reader (Biochrom, England). Optical density was converted to condensed tannins concentration (expressed as cyanidin) using a molecular extinction coefficient $\left(\varepsilon_{\text {mol }}\right)$ of $34,700 \mathrm{Lmol}^{-1} \mathrm{~cm}^{-1}$. Optical path length was calculated from a sample volume divided by surface area of a microplate well.

\section{Measurement of turbidity}

Turbidity of cashew apple juice was determined by measuring optical density at 450 $\mathrm{nm}$ using Anthos Zenyth microplate reader (Biochrom, England) (Jacquier et al., 2001). The sample volume was $200 \mu$ l. The turbidity was expressed as the optical property of the cashew apple juice.

\section{Statistical analysis}

Statistical analyses, including model prediction, correlation test, and Shapiro-Wilk normality test, were performed by $\mathrm{R}$ version 2.13.0 (The R Foundation for Statistical Computing, http://cran.r-project.org).

\section{RESULTS}

\section{Condensed tannins}

The actual and predicted values of condensed tannins are shown in Table 1. The tannin concentration decreased as the concentration of gelatin and mixing time increased (Figure 1). The mixing time affected the condensed tannin concentration, especially at low concentrations of the gelatin. Tannin concentration as a function of gelatin concentration and mixing time could be described by the following equation:

$$
\text { Tannin }=2.64-4.92 \mathrm{G}-0.0485 \mathrm{~T}+3.17 \mathrm{G}^{2}+0.0465 \mathrm{GT}
$$

where $\mathrm{G}$ is concentration of gelatin ( $\mathrm{g} / 100 \mathrm{ml}$ juice) and $\mathrm{T}$ is the mixing time (min). All terms in the model were significant $(P<0.05)$, except the interaction term. However, inclusion of this term in the model resulted in higher $\mathrm{R}^{2}(91.99 \%)$. Shapiro-Wilk test indicated the normality of the residuals, as shown in Table 2. These results indicated that the model was suitable for predicting the condensed tannin concentration after precipitating with gelatin powder. The lowest tannin concentration $(0.5 \mathrm{mg} / 100 \mathrm{ml})$ was obtained by mixing $100 \mathrm{ml}$ cashew apple juice with $0.67 \mathrm{~g}$ gelatin for $15 \mathrm{~min}$. 
Table 1. Experimental design and response value of condensed tannin.

\begin{tabular}{|c|c|c|c|c|}
\hline \multirow[t]{2}{*}{ No. } & \multirow{2}{*}{$\begin{array}{l}\text { Gelatin } \\
(\mathrm{g} / 100 \mathrm{ml})\end{array}$} & \multirow[t]{2}{*}{ Mixing time (min) } & \multicolumn{2}{|c|}{$\begin{array}{l}\text { Condensed tannin } \\
(\text { g cyanidin } / 100 \mathrm{ml})\end{array}$} \\
\hline & & & Actual & Predicted \\
\hline 1 & 0.0 & 5 & 2.400 & 2.397 \\
\hline 2 & 0.0 & 10 & 2.357 & 2.155 \\
\hline 3 & 0.0 & 15 & 2.080 & 1.912 \\
\hline 4 & 0.2 & 5 & 1.613 & 1.586 \\
\hline 5 & 0.2 & 10 & 1.115 & 1.390 \\
\hline 6 & 0.2 & 15 & 0.865 & 1.193 \\
\hline 7 & 0.4 & 5 & 0.888 & 1.028 \\
\hline 8 & 0.4 & 10 & 0.796 & 0.878 \\
\hline 9 & 0.4 & 15 & 0.699 & 0.728 \\
\hline 10 & 0.6 & 5 & 0.824 & 0.723 \\
\hline 11 & 0.6 & 10 & 0.787 & 0.620 \\
\hline 12 & 0.6 & 15 & 0.728 & 0.517 \\
\hline 13 & 0.8 & 5 & 0.720 & 0.672 \\
\hline 14 & 0.8 & 10 & 0.702 & 0.615 \\
\hline 15 & 0.8 & 15 & 0.656 & 0.559 \\
\hline 16 & 1.0 & 5 & 0.819 & 0.875 \\
\hline 17 & 1.0 & 10 & 0.796 & 0.864 \\
\hline 18 & 1.0 & 15 & 0.720 & 0.854 \\
\hline
\end{tabular}




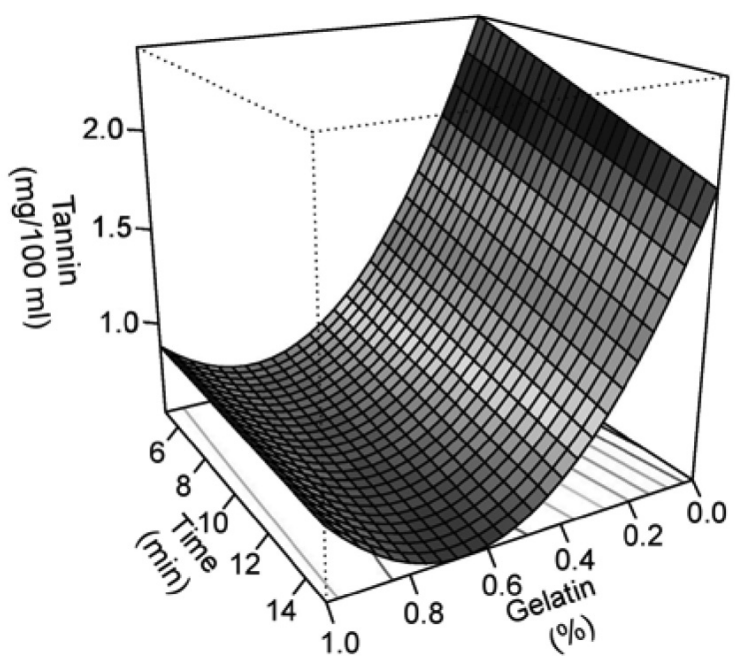

Figure 1. Condensed tannins as a function of mixing time and gelatin concentration.

Table 2. ANOVA of regression models.

\begin{tabular}{lccc}
\hline \multirow{2}{*}{ Terms } & \multicolumn{3}{c}{$\boldsymbol{P}$-value } \\
\cline { 2 - 4 } & Condensed tannin & OD $_{450}$ & Precipitate \\
\hline Model & $<2 \times 10^{-16}$ & $<2 \times 10^{-16}$ & $<2 \times 10^{-16}$ \\
Intercept & $<2 \times 10^{-16}$ & & 0.533 \\
Gelatin & $<2 \times 10^{-16}$ & $2.74 \times 10^{-12}$ & $<2 \times 10^{-16}$ \\
Time & $8.47 \times 10^{-6}$ & & \\
Gelatin $^{2}$ & $<2 \times 10^{-16}$ & $1.06 \times 10^{-9}$ & \\
Gelatin $^{3}$ & & $6.90 \times 10^{-10}$ & \\
Gelatin $^{4}$ & & $2.17 \times 10^{-11}$ & \\
Gelatin $^{-11}$ & & & \\
Adjusted R & & 0.9658 & 0.9498 \\
Shapiro-Wilk test of & 0.9199 & 0.1177 & 0.3295 \\
normality & 0.3013 & & \\
\hline
\end{tabular}

\section{Turbidity}

The actual and predicted values of turbidity $\left(\mathrm{OD}_{450}\right)$ of the cashew apple juice and gelatin-tannin precipitate are shown in Table 3. Analysis of variance revealed that mixing time had no significant effect on turbidity of cashew apple juice. Therefore, the regression model had only one independent variable (gelatin concentration) as in the following equation:

$$
\mathrm{OD}_{450}=0.157-1.177 \mathrm{G}+4.480 \mathrm{G}^{2}-7.140 \mathrm{G}^{3}+4.002 \mathrm{G}^{4}
$$


Table 3. Experimental design and response value of $\mathrm{OD}_{450}$ and precipitate.

\begin{tabular}{cccccc}
\hline \multirow{2}{*}{ Order } & \multirow{2}{*}{$\begin{array}{c}\text { Gelatin } \\
\text { concentration } \\
(\mathbf{g} / \mathbf{1 0 0} \mathbf{~ m l})\end{array}$} & \begin{tabular}{c}
\multicolumn{2}{c}{$\mathbf{O D}_{\mathbf{4 5 0}}$} \\
Actual \\
value
\end{tabular} & $\begin{array}{c}\text { Predicted } \\
\text { value }\end{array}$ & $\begin{array}{c}\text { Actual } \\
\text { value }\end{array}$ & $\begin{array}{c}\text { Predicted } \\
\text { value }\end{array}$ \\
\hline 1 & 0.0 & 0.157 & 0.157 & 0.0023 & 0.0008 \\
2 & 0.2 & 0.052 & 0.050 & 0.0182 & 0.0229 \\
3 & 0.4 & 0.045 & 0.049 & 0.0422 & 0.0384 \\
4 & 0.6 & 0.044 & 0.040 & 0.0474 & 0.0473 \\
5 & 0.8 & 0.065 & 0.066 & 0.0491 & 0.0497 \\
6 & 1.0 & 0.323 & 0.322 & 0.0455 & 0.0455 \\
\hline
\end{tabular}

Note: Data points were reduced from the experimental design because mixing time was excluded from the models.

Adding gelatin at $0.2 \%(\mathrm{w} / \mathrm{v})$ reduced the turbidity of cashew apple juice by $69.9 \%$; the turbidity slightly decreased after this point (Figure 2). Turbidity was reduced the most $(75.5 \%)$ with the addition of gelatin at $0.67 \%(\mathrm{w} / \mathrm{v})$.

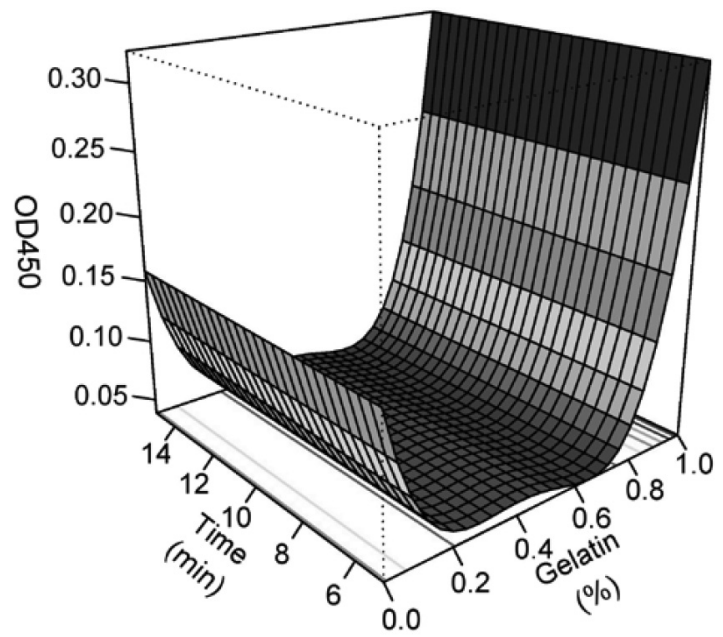

Figure 2. Turbidity of cashew apple juice after adding gelatin.

\section{Gelatin-tannin precipitate}

Gelatin-tannin precipitate increased with the gelatin concentration in the mixture. Mixing time had no significant effect on the precipitate and was excluded from the model. The precipitate could be predicted by the following equation:

Precipitate $=0.0008+0.127 \mathrm{G}-0.0819 \mathrm{G}^{2}$ 
The maximum weight of precipitate was obtained by adding $0.77 \%(\mathrm{w} / \mathrm{v})$ gelatin (Figure 3).

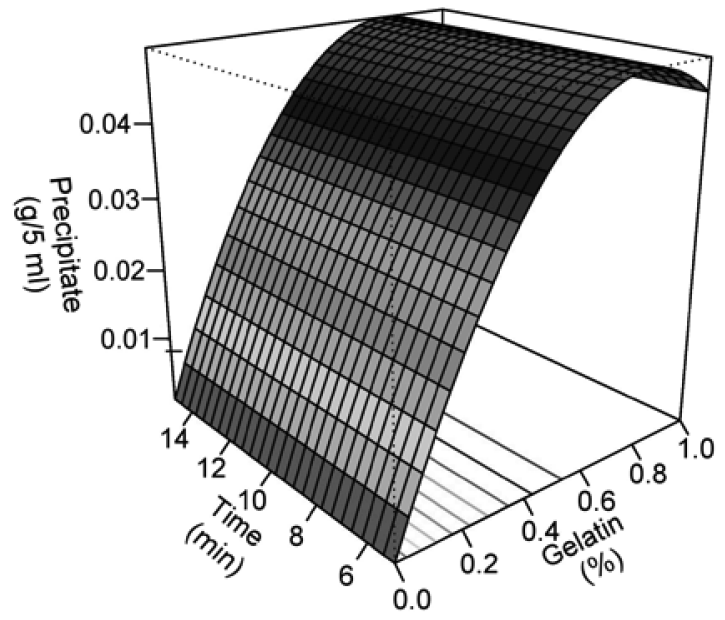

Figure 3. Gelatin-tannin precipitate formed after adding gelatin.

Condensed tannin concentration and precipitate weight correlated $(-0.902, P<0.001)$ as shown in Figure 4.

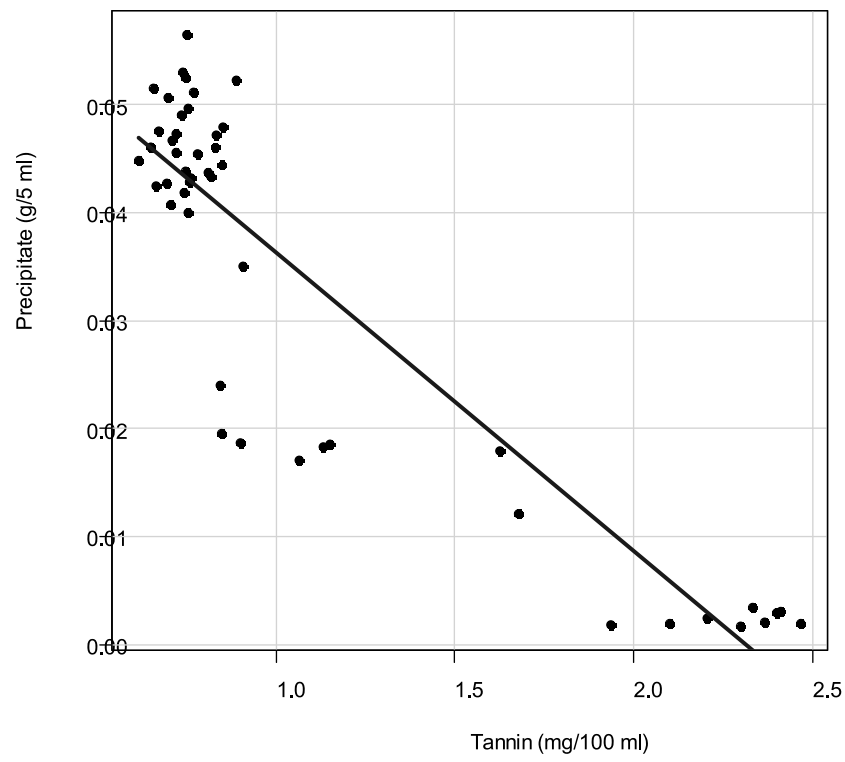

Figure 4. Correlation between tannin concentration and precipitate. 


\section{DISCUSSION}

Astringency of fruit juice is a result of the interaction between tannins in the juice and the salivary proteins and glycoproteins that lubricate the mouth, leading to a drying and puckering sensation (Fontoin et al., 2008). Astringency should be eliminated when tannins can no longer bind to the proteins. The maximum weight of the gelatin-tannin precipitate obtained in this study occurred with the addition of $0.77 \%(\mathrm{w} / \mathrm{v})$ gelatin. The weight of precipitate decreased after this point. Higher gelatin concentrations may serve as hydrocolloids that suspend the tannins within the juice rather than settling down the aggregates, resulting in higher turbidity and lower precipitate (de Freitas et al., 2003).

Similar behavior was found in haze formation between gelatin and tannic acid. The haze rose when the concentration of gelatin or tannic acid increased, until it reached a plateau. At this point, the binding site of tannins was equivalent to the binding site of gelatin, forming the largest network, which caused maximum light scattering. The insufficient binding sites of tannins to bridge all gelatin molecules together in the condition of higher gelatin concentration resulted in smaller aggregate formation within the mixture (Siebert et al., 1996a).

All terms in the model to predict the efficiency of gelatin at reducing tannins from cashew apple juice in this study were significant $(P<0.05)$ and the model resulted in higher $\mathrm{R}^{2}(91.99 \%)$. Shapiro-Wilk test indicated that the model was suitable for predicting the condensed tannin concentration after tannins were precipitated by adding gelatin powder (Table 2). Adding gelatin at $0.2 \%(\mathrm{w} / \mathrm{v})$ reduced turbidity of cashew apple juice by $69.9 \%$; the turbidity slightly decreased after this point (Figure 2$)$. The lowest tannin concentration $(0.5$ $\mathrm{mg} / 100 \mathrm{ml}$ ) was obtained by mixing $100 \mathrm{ml}$ cashew apple juice with 0.67 g gelatin for $15 \mathrm{~min}$.

Augustin (1982) clarified cashew apple juice using polyvinyl pyrolidone (PVP); Jayalekshmy and John (2004) reported sago was an efficient and economic clarifying agent. Talasila et al. (2012) compared various clarifying agents and found that sago at a concentration of $2 \mathrm{~g} / \mathrm{L}$ decreased tannins by $42.9 \%$, and was more efficient than a higher concentration (4 $\mathrm{g} / \mathrm{L}$ ). Talasila et al. (2012) found that gelatin and PVP at concentrations of $4 \mathrm{~g} / \mathrm{L}$ decreased tannins by 37.4 and $31.9 \%$, respectively, and that starch at either concentration $(2$ or $4 \mathrm{~g} / \mathrm{L})$ was not effective.

Turbidity is an important factor in determining the quality of fruit juice. In this study, the mixing time did not significantly affect the turbidity of the cashew apple juice. Therefore, the regression model had only one independent variable - gelatin concentration. Adding gelatin reduced the turbidity until reaching a maximum reduction of $75.5 \%$ by adding $0.67 \%$ (w/v) gelatin; thereafter the turbidity increased again. The Gelatin-tannin precipitate increased with gelatin concentration, while the mixing time had no significant effect. The maximum weight of precipitate was obtained after adding $0.77 \%(\mathrm{w} / \mathrm{v})$ gelatin (Figure 3 ).

The most effective strategy in our study for removing tannins from cashew apple juice was to add gelatin $(0.67 \mathrm{~g} / 100 \mathrm{ml}$ juice $)$ and mix for 15 minutes, yielding a tannin concentration of $0.5 \mathrm{mg} / 100 \mathrm{ml}$. This was higher than in juice clarified by enzyme tannase and microfiltration $(0.2 \mathrm{mg} / 100 \mathrm{~g})$ (Campos et al., 2002). Although our method did not reduce the tannins as much as the enzymatic pretreatment, it offers an effective and inexpensive alternative. Condensed tannin concentration and precipitate weight had a negative correlation 
(the lower the condensed tannin in the juice, the higher the precipitate formed), indicating that condensed tannin in the juice was formed into the precipitate. This result was similar to complexation of canola tannins by bovine serum albumin (Naczk et al., 1996). The decrease of tannins could be due to the formation of insoluble tannin-protein complexes, which are precipitated and filtered later (Hagerman and Butler, 1978).

Different clarification treatments differed in their effectiveness at decreasing the astringency of cashew apple juice. For example, differences in the efficiency of sago (2 $\left.\mathrm{mgL}^{-1}\right)$ (Jayalekshmy and John, 2004) and gelatin $\left(4 \mathrm{mgL}^{-1}\right)$ (Cormier, 2008) in decreasing astringency might be due to differences in cashew apple cultivar and the chemical composition of the clarifying agents used; tannins are precipitated by sago, flocculated by gelatin and starch, and chelated by PVP (Jayalekshmy and John, 2004). The efficiency of clarifying agents also depends on their concentration and composition, the characteristics of the tannins (size, structure, and heterogeneity), and conditions of the interaction $(\mathrm{pH}$, temperature, and juice composition) (Talasila et al., 2012).

At higher gelatin concentrations, the tannins remained within the juice in the form of a complex with the gelatin. These remaining tannins should not cause astringency, as they can no longer bind to salivary protein. This phenomenon is similar to the salivary proline-rich protein that formed complexes with tannins in food, preventing the tannins from binding with digestive enzymes (Bennick, 2002). However, turbidity of the juice might affect consumer acceptance of the product (Siebert et al., 1996b), thus gelatin should be added at the amount that eliminates tannins without forming haze.

In our study, adding gelatin to cashew apple juice decreased the tannin concentration in the juice and formed gelatin-tannin complexes, with the added benefit of juice clarification. The minimum concentration of tannins and turbidity was obtained by mixing gelatin at $0.67 \%$ $(\mathrm{w} / \mathrm{v})$ for $15 \mathrm{~min}$. The tannin concentration $(0.5 \mathrm{mg} / 100 \mathrm{ml})$ in cashew apple juice achieved using gelatin in this study is low enough for producing cashew apple wine and bioethanol.

\section{ACKNOWLEDGEMENTS}

The authors gratefully acknowledge the financial support and/or in-kind assistance of the National Research Council of Thailand (NRCT), Project Funding of National Research University - Chiang Mai University (NRU-CMU), National Research University - Office of Higher Education Commission, Ministry of Education, Thailand (NRU-OHEC), Non-Food Agricultural Research Cluster, Chiang Mai University (CMU), and Bioprocess Research Cluster (BRC). The authors would like to express their appreciation to Dr. Pilairuk Intipunya for her useful suggestions in preparing this research paper. 


\section{REFERENCES}

Augustin, A. 1982. Studies on the clarification of cashew apple for the preparation of cashew syryp. The Indian Journal of Nutrition and Dietetics. 19(6): 169-172.

Bennick, A. 2002. Interaction of plant polyphenols with salivary proteins. Critical Reviews in Oral Biology \& Medicine. 13(2): 184-196.

Campos, D.C.P., Santos, A.S., Wolkoff, D.B., Matta, V.M., Cabral, L.M.C., and Couri, S. 2002. Cashew apple juice stabilization by microfiltration. Desalination. 148(1-3): 61-65. https://doi.org/10.1016/S0011-9164(02)00654-9

Cormier, R. 2008. Clarification of cashew apple juice and commercial applications. Springer, Benin., pp. 1-9.

de Freitas, V., Carvalho, E. , and Mateus, N. 2003. Study of carbohydrate influence on proteintannin aggregation by nephelometry. Food Chemistry 81(4): 503-509.

Figueiredo, R.W.D., Lajolo, F.M., Alves, R. E., and Filgueiras, H.A.C. 2002. Physical-chemical changes in early dwarf cashew pseudofruits during development and maturation. Food Chemistry. 77(3): 343-347. https://doi.org/10.1016/S0308-8146(01)00358-2

Fontoin, H., Saucier, C., Teissedre, P.L., and Glories, Y.2008. Effect of pH, ethanol and acidity on astringency and bitterness of grape seed tannin oligomers in model wine solution. Food Quality and Preference. 19(3): 286-291. https://doi.org/10.1016.j.foodqual.2007.08.004

Hagerman, A.E. 2011. The Tannin Handbook. [online] Available at http://www.users.muohio. edu/hagermae/ (23 July 2011).

Hagerman, A.E., and Butler, L.G. 1978. Proteine precipitation method for the quantitative determination of tannins. Journal of Agricultural and Food Chemistry. 26(4): 809-812. https://doi.org/10.1021/jf60218a027

Inyang, U.E., and Abah, U.J. 1997. Chemical composition and organoleptic evaluation of juice from steamed cashew apple blended with orange juice. Plant Foods for Human Nutrition. 50: 295-300.

Jacquier, J.C., MacArtain, P., and Dawson, K.A. 2001. Hydrophobically modified calciuminduced $\kappa$-carrageenan gels. Trends in Colloid and Interface Science XV. Springer, Berlin.

Jayaleshmy, V.G., and John, P.S. 2004. 'Sago' - a natural product for cashew apple juice clarification. Journal of Tropical Agriculture. 42(1-2): 67-68.

Naczk, M., Oickle, D., Pink, D., and Shahidi, F. 1996. Protein precipitating capacity of crude canola tannins: Effect of $\mathrm{pH}$, tannin, and protein concentrations. Journal of Agricultural and Food Chemistry. 44(8): 2144-2148. https://doi.org/10.1021/jf960165k

Prommajak, T., Leksawasdi, N., and Rattanapanone, N. 2014. Biotechnological vlorization of cashew apple: a Review. Chiang Mai University Journal of Natural Science. 13(2): 159-182. https://doi.org/10.12982/CMUJNS.2014.0029

Rocha, M.V., Souza, M.C., Benedicto, S.C., Bezerra, M.S., Macedo, G.R., Pinto, G.A., and Gonçalves, L.R. 2007. Production of biosurfactant by Pseudomonas aeruginosa grown on cashew apple juice. Applied Biochemistry and Biotechnology. 136-140(1-12): 185194. https://doi.org/10.1007/S12010-007-9050-6

Shahidi, F., and Naczk, M. 2004. Phenolics in food and nutraceuticals. CRC Press, Boca Raton. 
Siebert, K.J., Carrasco, A., and Lynn, P.Y. 1996a. Formation of protein-polyphenol haze in beverages. Journal of Agricultural and Food Chemistry. 44(8): 1997-2005. https://doi. org/10.1021/jf950716r

Siebert, K.J., Troukhanova, N.V., and Lynn, P.Y. 1996b. Nature of polyphenol-protein interactions. Journal of Agricultural and Food Chemistry. 44(1): 80-85. https://doi. org/10.1021/jf9502459

Talasila, U., Vechalapu, R.R., and Shaik, K.B. 2012. Clarification, preservation, and shelf life evaluation of cashew apple juice. Food Science and Biotechnology. 21(3): 709-714. https://doi.org/ 10.1007/S10068-012-0092-3

Vermerris, W., and Nicholson, R. 2006. Phenolic compound biochemistry. Springer, Dordrecht. 